\title{
Design and Simulation of Cyclic Battery Tester
}

Research Article

Juraj Bilansky*, Milan Lacko

Department of Electrical Engineering and Mechatronics, Faculty of Electrical Engineering and Informatics, Technical University of Košice, Letná 9 , 042 00, Košice, Slovak Republic

Received: November 22, 2020; Accepted: December 07, 2020

Abstract: The paper presents an approach to the modelling of a cyclic battery tester and contains observations about lithium-ion (Li-ion) batteries, charging/discharging procedures, conditions and protections which must be observed during the testing process. The main goal was to create and simulate a schematic which will be capable of cyclically testing Li-ion battery cells. Regulation of the final schematic is based on cascade connections of operation amplifiers, which work as a voltage source with current-limiting functions. The power part is created by two MOSFETs connected as a half-bridge. This topology allows current to flow in both directions (from and to the battery). Final simulation is supplemented by protections such as reverse polarity protection, short circuit protection and overvoltage protection during charging. Proper operation of the whole connection is demonstrated by the simulation outputs in the final section.

Keywords: battery $\bullet$ cell $\bullet$ charging $\bullet$ discharging $\bullet$ Simscape

\section{Introduction}

In recent years, batteries have become a very important part of our lives. They provide power for the portable electronic devices that we use everyday. For example, we can mention mobile phones, laptops, watches, electric cars and much more. With increasing technological advancements in portable electronic devices, the market for affordable batteries is also growing. Many different types of batteries are available on the market today, such as nickel-cadmium ( $\mathrm{NiCd}$ ), nickel-metal hydride ( $\mathrm{NiMh}$ ) or lithium-ion (Li-ion). The latter Li-ion batteries make up the majority of the market. They are used in mobiles, laptops and many other industries. These batteries are also used in electric vehicles. This article is focused on Li-ion batteries, which are found in electric vehicles (electric cars, electric scooters, electric bicycles and so on). These batteries are usually large, heavy and make up a significant part of the vehicle's weight. They are located in the floor and thus reduce the centre of gravity of the whole vehicle; this reduction has a positive effect on driving characteristics compared to the large weight. Batteries used in electric vehicles are called traction batteries (the energy of these batteries is transformed into kinetic energy). Traction batteries (depending on the size of the vehicle) consist of a large number of small battery cells which, by suitable series-parallel connection, form an electric vehicle battery with the required properties such as output voltage, current and capacity. Manufacturers must find the right ratio between battery capacity and weight when designing a battery, since the larger the battery, the heavier the vehicle and the higher the energy consumption. Final battery quality, then, defines the basic characteristics of the vehicle such as power, range and weight. From the point of view of cyclic testing of batteries, this process is energy, time and financially demanding (the battery pack is expensive, in the case of an electric car it is also heavy and has a high capacity) therefore, we will simplify testing and we will test the basic building blocks of these batteries, namely battery cells itself. 


\section{Li-Ion Battery}

Li-ion batteries can provide excellent levels of performance and a long lifetime. To achieve maximum life, they must be properly charged and discharged. Available chargers are usually made with the goal of the fastest charging process, regardless of the effects on the battery. In addition, manufacturers strive for maximum versatility of chargers, which is not a correct approach, because different types of batteries also have different types of charging processes. All batteries gradually lose their properties by cyclic charging and discharging, and in cases of incorrect use, this is doubly true. In the case of Li-ion batteries, their lifespan is approximately 500-1000 cycles, depending on the exact composition of the battery. This section focuses on the proper process of charging and discharging Li-ion batteries and also the protections that must be provided during these processes, as can be seen in Figure 1. Li-ion batteries are produced in different shapes (cylindrical, prismatic, button and so on) and in most cases, they usually have a nominal voltage of around 3.7 V (Bil'anský, SCYR, 2020).

\section{Advantages of Li-ion batteries}

+ Relatively high operating voltage $(2.5-4.2 \mathrm{~V})$

+ High power density and no memory effect

+ Great charging/discharging characteristics and self-discharging only at $1-2 \%$ per month

+ Wide range of operating temperatures from $-20^{\circ} \mathrm{C}$ to $+60^{\circ} \mathrm{C}$

Disadvantages of Li-ion batteries

- Cells must be protected

- Ageing of cells: lifespan is $500-1000$ cycles; the more the number of cycles, the less the remaining capacity

- Price per cell

\subsection{Charging}

The correct charging process according to the manufacturers consists of two phases (Luan et al., 2011). This type of charging is called constant current (CC)/constant voltage (CV) charging. CC/CV charging characteristics are shown in Figure 2.

a) $\mathrm{CC}$ phase: $\mathrm{CC}$ flows from the charging source to the battery with a voltage higher than the battery nominal voltage. Usually, this current is in the range of $0.5-1 \mathrm{C}$ depending on the battery. The current value affects

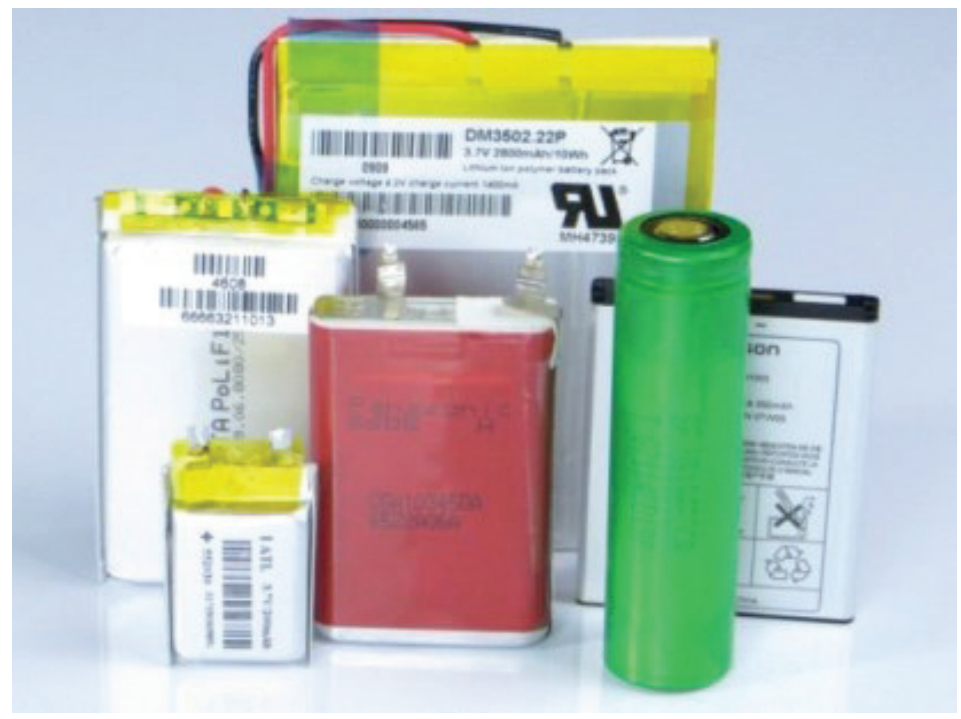

Fig. 1. Different shapes of batteries (Anon, 2020). 


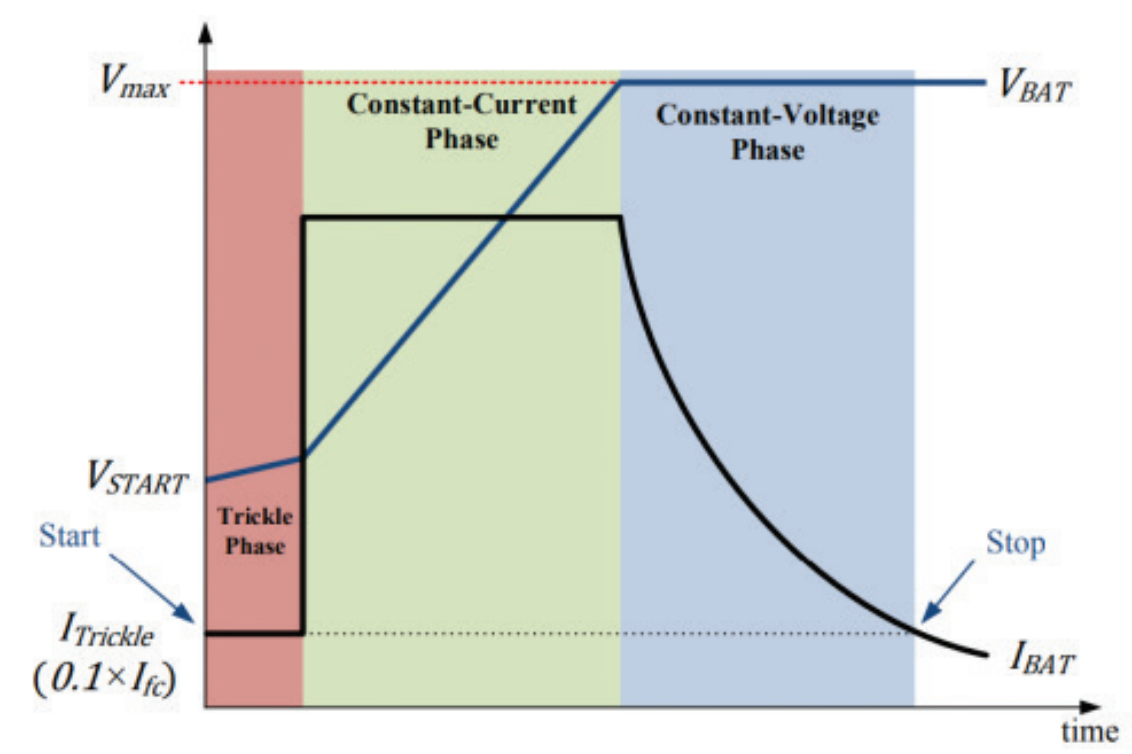

Fig. 2. Proper charging characteristics of Li-ion battery (Tar and Fayed, 2016).

the charging speed. Most of the manufacturers recommend choosing a maximum charging current of $0.5 \mathrm{C}$. During this phase, the current must be of constant magnitude and direction. The battery voltage starts to increase. This phase ends when the battery voltage reaches the maximum specified by the manufacturer. For Li-ion batteries the maximum voltage is usually in the range of $4.1-4.3 \mathrm{~V}$ depending on the type of battery (Khan et al., 2016; Luan et al., 2011).

b) CV phase: The charged battery is connected to the CV charging source with a voltage value of maximally allowed battery voltage. Charging current starts to decrease. This phase ends when charging current, which flows to the battery, is only $0.01 \mathrm{C}$. This second phase is not always desired, because it can add only about $10 \%$ of capacity to the battery, but it stresses the battery and thus slightly reduces lifespan (Khan et al., 2016; Luan et al., 2011).

After charging, it is advisable to leave the battery disconnected for a while without any load.

\subsubsection{Charging protection}

Since the battery needs to be handled with care, some important protections need to be provided during charging. These protections will guarantee the battery's maximum lifespan and capacity.

a) Regulation of charging current: Charging current must be constant and limited. A typical value is $0.5 \mathrm{C}$ (Ye et al., 2010).

b) Temperature protection: The temperature of the battery cell should be monitored during charging and in case of high temperature it should be disconnected. Batteries should not be charged if the cell temperature is below $0^{\circ} \mathrm{C}$ or above $45^{\circ} \mathrm{C}$ (Ye et al., 2010).

c) Overcharge protection: This protection aims to ensure that the voltage at the battery terminals does not exceed 4.3 V (Ye et al., 2010).

d) Reverse polarity protection: It disconnects the battery in case of incorrect connection.

\subsection{Discharging}

Modern Li-ion batteries can handle a wide range of discharge currents. Discharging characteristics are shown in Figure 3. Manufacturers usually determine the optimal value of the battery discharge current. This value is a multiple of the constant C (for a $2200 \mathrm{mAh}$ battery the value of the battery discharge current is $1 \mathrm{C}=2200 \mathrm{~mA}$ ) (Meena et al., 2014). At this value, the manufacturer guarantees the life of the individual cells. Of course, it can be discharged with a current higher than $1 \mathrm{C}$, but the result will be a higher battery temperature at large discharge 


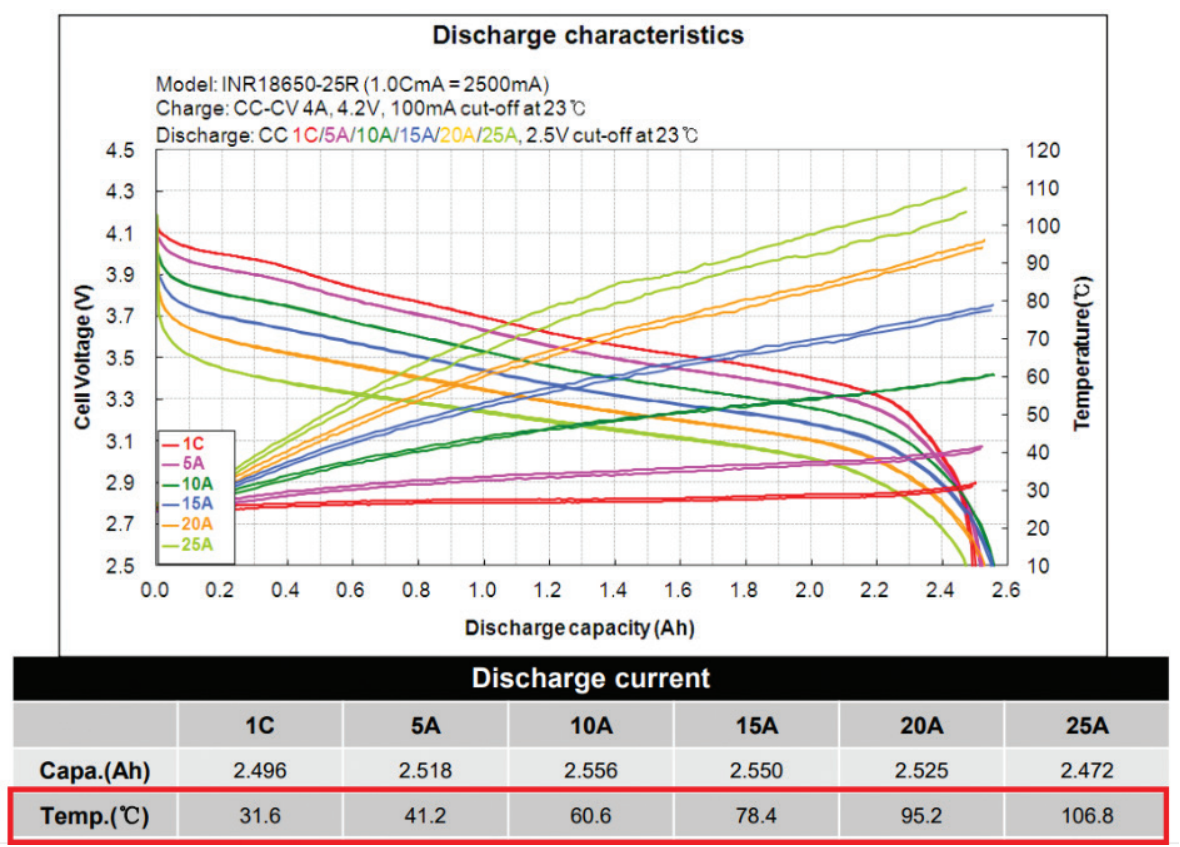

Fig. 3. Discharge characteristics for different currents for the battery Samsung INR18650-25R (INR18650-25R, 2014).

currents; the temperature may extend up to $100^{\circ} \mathrm{C}$. A higher discharge current also affects the battery capacitance after a few tens of cycles (Wey and Jui, 2013).

\subsubsection{Discharging protection}

The discharge process must be controlled because incorrect discharging can lead to significant damage to the battery or may even cause a fire. Battery fires are a serious problem because they cannot be extinguished classically.

a) Short Circuit protection: Li-ion batteries are sensitive to short circuits; therefore, protection is needed to take action in the case of a hard short circuit (Hsieh et al., 2011).

b) Temperature protection: The temperature of a battery cell must not exceed $100^{\circ} \mathrm{C}$. A temperature higher than $100^{\circ} \mathrm{C}$ can cause damage to the internal structure of the cell. This damage can lead to a battery fire (Hsieh et al., 2011).

c) Undercharge protection: Protection is given to ensure that the voltage at the battery terminals does not fall below the minimum value of $2.5 \mathrm{~V}$.

d) Reverse polarity protection (Xiong et al., 2012).

\section{Design and Simulation}

The proper method to charge and discharge batteries was described in the previous sections.

In this section, the charging and discharging system will be designed, and its functionality will be tested on the MATLAB simulations in the Simscape extension.

\subsection{Requirements}

During charging and discharging, it is necessary to observe certain conditions of the battery to ensure that it is not excessively damaged; thus, by observing these conditions, it becomes possible to avoid unwanted ageing and reduced capacity. The most important factors during cyclic testing are summarised below.

a) $\mathrm{CC} / \mathrm{CV}$ charging

b) $\mathrm{CC}$ discharging 
c) Reverse polarity protection

d) Overcharge and undercharge protection

e) Temperature protection

\subsection{Battery simulation settings}

The first and basic element is the battery. Since it is necessary to bring the simulation closer to reality, it is advisable to choose a real battery and enter its parameters into the model. As can be seen in Figure 4, the Samsung INR18650$25 \mathrm{R}$ battery was chosen.

In Simscape there are two blocks for battery modelling. In this simulation, a table-based battery model was chosen. The setting of the block is shown below in Figure 5.

\begin{tabular}{|c|c|c|c|}
\hline \multicolumn{2}{|r|}{ Type } & Spec. & Typical INR18650-25R \\
\hline Chemistry & & NCA & NCA \\
\hline \multicolumn{2}{|c|}{ Initial IR (m $\Omega$ AC $1 \mathrm{kHz})$} & $\leq 18$ & $13.20 \pm 2$ \\
\hline \multicolumn{2}{|c|}{ Initial IR (m $\Omega$ DC (10A-1A)) } & $\leq 30$ & $22.15 \pm 2$ \\
\hline \multicolumn{2}{|c|}{ Nominal Voltage (V) } & 3.6 & 3.64 \\
\hline \multicolumn{2}{|c|}{ Charge Method (100mA cut-off) } & CC-CV $(4.2 \pm 0.05 \mathrm{~V})$ & $\mathrm{CC}-\mathrm{CV}(4.2 \pm 0.05 \mathrm{~V})$ \\
\hline \multirow{2}{*}{ Charge Time } & Standard (min), 0.5C & $180 \mathrm{~min}$ & $134 \mathrm{~min}$ \\
\hline & Rapid (min), 4A & $60 \mathrm{~min}$ & $55 \mathrm{~min}$ \\
\hline \multirow{2}{*}{ Charge Current } & Standard current (A) & 1.25 & 1.25 \\
\hline & Max. current (A) & 4.0 & 4.0 \\
\hline \multirow{3}{*}{ Discharge } & End voltage (V) & 2.5 & 2.5 \\
\hline & Max. cont. current (A) & 20 & 20 \\
\hline & $\begin{array}{l}\text { Max. momentary pulse } \\
\text { (A, <1sec) }\end{array}$ & 100 & 100 \\
\hline \multirow{2}{*}{ Rated discharge Capacity } & Standard (mAh) (0.2C) & 2,500 & 2.560 \\
\hline & rated $(m A h)(10 A)$ & 2,450 & 2.539 \\
\hline
\end{tabular}

Fig. 4. Important parameters from the datasheet of Samsung INR18650-25R (INR18650-25R, 2014).

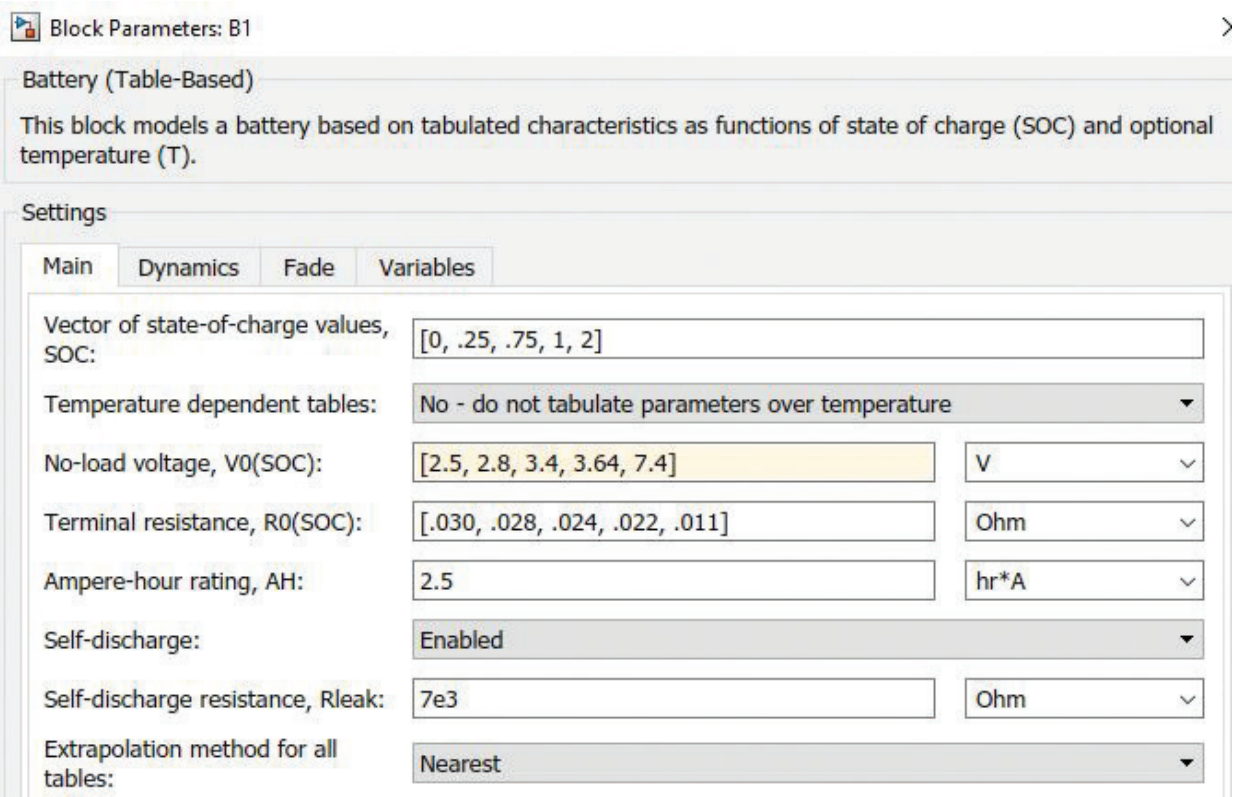

Fig. 5. Important parameters from the datasheet of Samsung INR18650-25R (INR18650-25R, 2014). 


\subsection{Reverse polarity protection}

Reverse polarity protection is very important because the incorrectly connected battery cannot work properly. Further, such a battery can be dangerous because in badly designed systems which lack protections, incorrect battery connections can cause short circuits, which can lead to a fire. The easiest way to protect the battery from incorrect connections is to use a diode. The problem with using a diode is that current can flow only in one direction, namely from the battery to the load. Since the battery needs to be charged, it is necessary to find some solution that allows conduction of current in both directions. Some options that are worthy of mention are listed below:

a) Electromagnetic relay with the control circuit

b) MOSFET with the control circuit

From these two options, we used the MOSFET variant, because MOSFET has no mechanical parts which can wear out and also because MOSFET has a smaller package than the relay. Further, MOSFET has low power control, and some resistance in on state which is marked as $R_{D S(o n)}$. In this case, $R_{D S(o n)}$ has a small value and can be used as short circuit protection. Therefore, MOSFET can deal with two protections. The problem with the MOSFET variant is that a fully open MOSFET needs a $V_{G S}$ control voltage of about $\pm 15 \mathrm{~V}$, depending on the polarity of the MOSFET. Since those Li-ion batteries will be used whose voltage is in the range of 2.5-4.2 $\mathrm{V}$ depending on the charge and battery type, MOSFETs that have a very low threshold voltage $V_{G S(t h)}$ and relatively low resistance $R_{D S(\text { on) }}$ at a control voltage $V_{G S}=2.5 \mathrm{~V}$ must be chosen. The N-channel Si7858BDP MOSFET was chosen. This MOSFET has a relatively low $R_{D S(o n)}$ even at a voltage of $2.5 \mathrm{~V}$, which is the minimum voltage that is reached during the discharge of cells. All relevant information is shown in Figure 6. Such a MOSFET must be supplemented with a control circuit. The connection that can be found in Figure 7 was designed, which will be simulated in Simscape to prove functionality (Figure 8).

\begin{tabular}{|c|c|c|c|c|c|c|}
\hline \multicolumn{5}{|c|}{ ABSOLUTE MAXIMUM RATINGS } & \multicolumn{2}{|l|}{ PRODUCT SUMMARY } \\
\hline \multicolumn{2}{|l|}{ PARAMETER } & SYMBOL & LIMIT & UNIT & $V_{D S}(\mathrm{M})$ & 12 \\
\hline \multicolumn{2}{|l|}{ Drain-source voltage } & $V_{D S}$ & 12 & \multirow{2}{*}{$\mathrm{v}$} & $R_{D S \text { (on) }} \max .(\Omega)$ at $V_{G S}=4.5 \mathrm{~V}$ & 0.0025 \\
\hline \multicolumn{2}{|l|}{ Gate-source voltage } & $V_{G S}$ & \pm 8 & & $R_{D S(o n)} \max .(\Omega)$ at $V_{G S}=2.5 \mathrm{~V}$ & 0.0030 \\
\hline \multirow{4}{*}{ Continuous drain current $\left(T_{J}=150^{\circ} \mathrm{C}\right)$} & $T_{C}=25^{\circ} \mathrm{C}$ & \multirow{4}{*}{$I_{D}$} & $40^{a}$ & \multirow{7}{*}{ A } & $R_{D S \text { (on) }} \max .(\Omega)$ at $V_{G S}=1.8 \mathrm{~V}$ & 0.0037 \\
\hline & $T_{C}=70^{\circ} \mathrm{C}$ & & $40^{a}$ & & $Q_{g}$ typ. (nC) & 56 \\
\hline & $T_{A}=25^{\circ} \mathrm{C}$ & & $33^{\mathrm{b}, \mathrm{c}}$ & & $I_{D}(\mathrm{~A})^{\mathrm{a}}$ & 40 \\
\hline & $T_{A}=70^{\circ} \mathrm{C}$ & & $26^{\mathrm{b}, \mathrm{c}}$ & & Configuration & Single \\
\hline \multicolumn{2}{|l|}{ Pulsed drain current } & $I_{D M}$ & 70 & & \multirow[t]{7}{*}{ PowerPAK ${ }^{\oplus}$ so- 8 Single } & \\
\hline & $T_{C}=25^{\circ} \mathrm{C}$ & & $40^{a}$ & & & \\
\hline Continuous source-drain diode current & $T_{A}=25^{\circ} \mathrm{C}$ & $I_{5}$ & $4.5^{b}, \mathrm{c}$ & & & \\
\hline \multirow{4}{*}{ Maximum power dissipation } & $T_{C}=25^{\circ} \mathrm{C}$ & \multirow{4}{*}{$P_{D}$} & 48 & \multirow{4}{*}{ W } & & \\
\hline & $T_{C}=70^{\circ} \mathrm{C}$ & & 31 & & & \\
\hline & $T_{A}=25^{\circ} \mathrm{C}$ & & $5^{b, c}$ & & & \\
\hline & $T_{A}=70^{\circ} \mathrm{C}$ & & $3.2^{b, c}$ & & & \\
\hline
\end{tabular}

Fig. 6. Important parameters from the datasheet of Si7858BDP MOSFET (Si7858BDP, 2019).

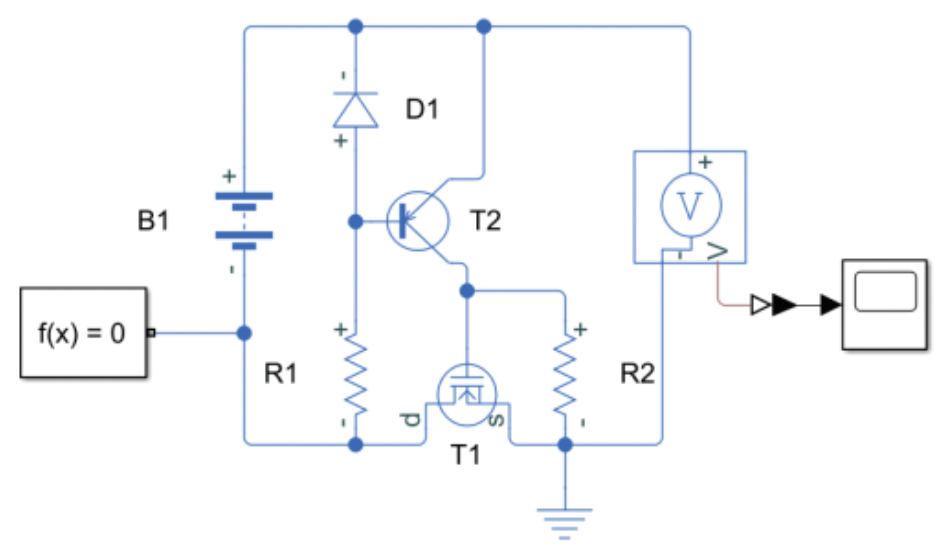

Fig. 7. The simulated schematic in Simscape. 
If the battery is correctly polarised, diode $D_{1}$ is closed and base current flows through resistor $R_{1}$ to the ground. Consequent to this, current in PNP transistor $T_{2}$ is opened and current can flow between emitter and collector. This current flows through resistor $R_{2}$ to the ground and creates a voltage drop; this voltage is labelled as $V R_{2}$ which equals the MOSFET control voltage $V_{G S}$ and actual battery voltage.

$$
V_{R_{2}}=V_{G S}=V_{B A T}
$$

Since this voltage is greater than the $V_{G S(t h)}$ MOSFET, $T_{1}$ opens and the resistance $R_{D S(o n)}$ is reduced to a value which is, according to the datasheet, $0.003 \mathrm{Ohm}$. In case of incorrect polarisation, diode $D_{1}$ is opened. Since the diode is opened, the base current flows through the diode back to the emitter of $T_{2}$. There is no current that flows to the ground, and transistor $T_{2}$ is closed. If $T_{2}$ is closed, there is no current that flows through $R_{2}$.

$$
V_{R_{2}}=V_{G S}=0
$$

Since the MOSFET body diode is for a battery which is negatively polarised, the last way of battery on the output is closed.

\subsection{CC/CV charging and CC discharging}

In order to test the batteries cyclically, they must be charged and discharged. Many topologies can handle these requirements. One of the easiest topologies that is able to charge and discharge batteries is known as a twoquadrant DC-DC converter or a H-Bridge topology; this is shown in Figure 9.

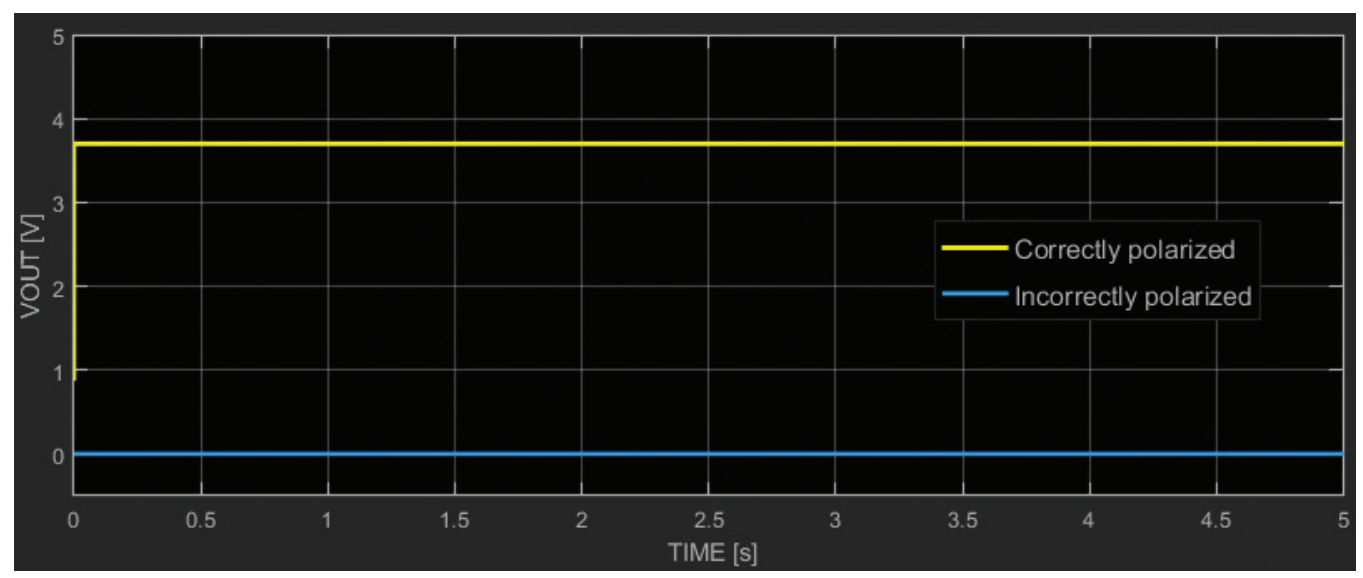

Fig. 8. Simulation output: reverse polarity protection.

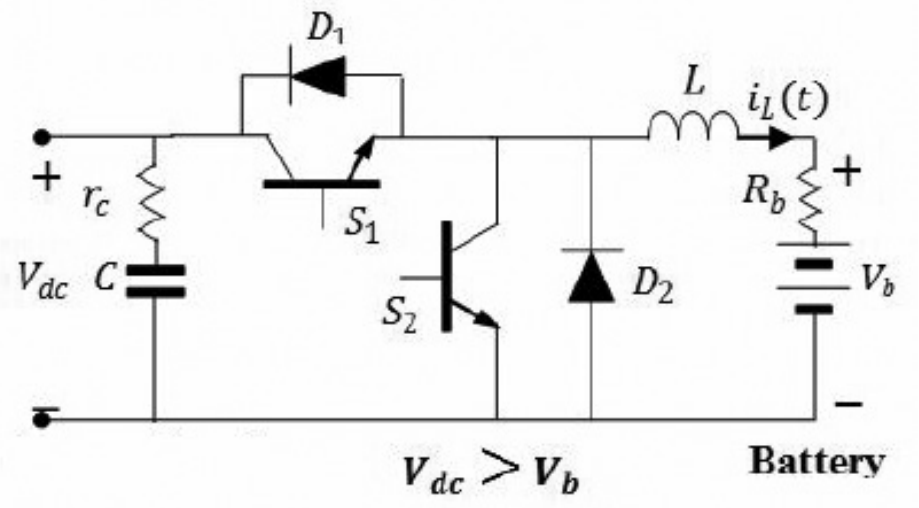

Fig. 9. Two-quadrant DC-DC converter (Mahmoud and Osama, 2011). 
The topology available in the literature has been modified. The main change is to use MOSFETs with body diodes instead of transistor-diode pairs, on account of charging and discharging the low voltage battery. Since linear discharging and charging currents are required, operational amplifiers are used as control elements; these provide stable and smooth current regulation in the linear region of MOSFET transistors. The regulation circuit is based on the operation amplifier, which is connected as $P$ regulator. $I C_{1}$ gain is set to 200 . The controller is supplemented by a current sensor and a reference voltage source, which determine the state and whether the battery is being charged or discharged by the polarity of the reference voltage. Consequent to the voltage divider, which is created by resistors $R_{1}$ and $R_{2}$, it is possible to use any current sensor with an analogue DC output. In the real world, the reference voltage for the current regulator can be set using a potentiometer or an MCU (Microprocessor unit) with DAC (Digital to analog converter). In the circuit there is also a SPDT (Single Pole Double Throw) switch, which connects the gates of MOSFETs to the source signal from $I C_{1}$, depending on whether charging or discharging is required. The complete connection is shown in Figure 10. This circuit works as a constant current source that can maintain the setpoint current on the output, as can be seen in Figure 11. Currents are stable and discharging is okay, but in the charging process, it is possible to observe that voltage is rising over maximal battery voltage, which is very undesirable.

The proper charging process consists of two phases ( $\mathrm{CC}$ and $\mathrm{CV}$ ) (Figure 2). It is necessary to add a voltage subregulator to the cascade along with the current regulator; this will ensure that during charging, when the voltage setpoint value is reached, the charging switches from CC mode to $\mathrm{CV}$ mode. The voltage regulator consists of $I C_{2}$, voltage feedback from the charged battery, which is connected through a voltage divider $\left(R_{5}\right.$ and $\left.R_{6}\right)$ to $I C_{2}$, and the reference voltage source with respect to $R_{4}$. The circuit acts as a constant voltage source that maintains a setpoint which is set with the reference $V_{S E T}$. In the case of current limitation, the controller $I C_{1}$ starts to control the controller $I C_{2}$ via the diode $D_{1}$; thus, the value from the current sensor does not change, and therefore the circuit is in the state of a CC source. Consequent to this connection, it is possible to set a constant charging/discharging current and also the voltage at which the circuit switches from CC mode to CV mode during the charging procedure. The final simulation schematic is shown in Figure 12. As can be seen in Figure 13, the charging procedure is now correct,

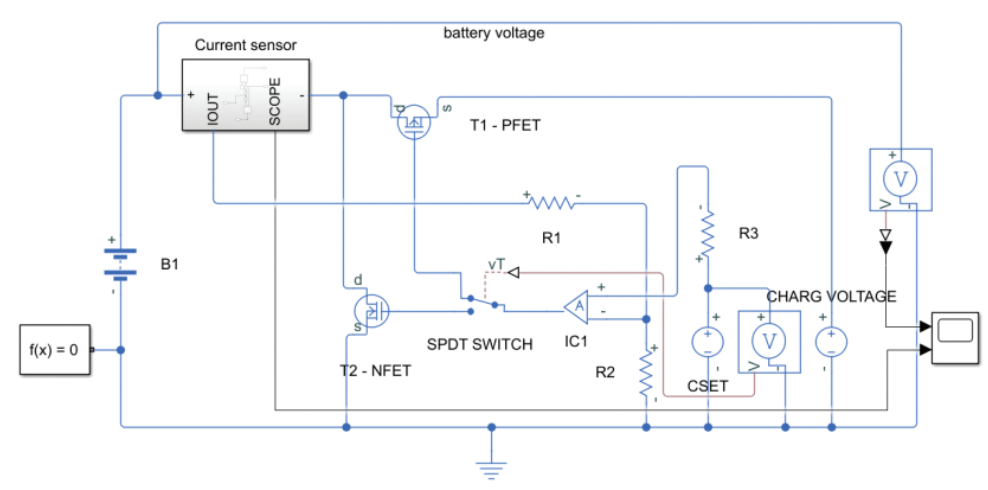

Fig. 10. Simulation schematic: CC charging and discharging.

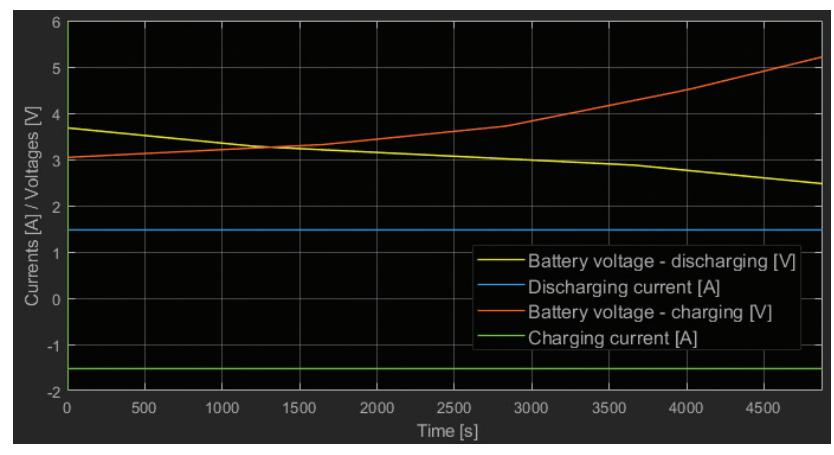

Fig. 11. Simulation output: CC charging and discharging. 


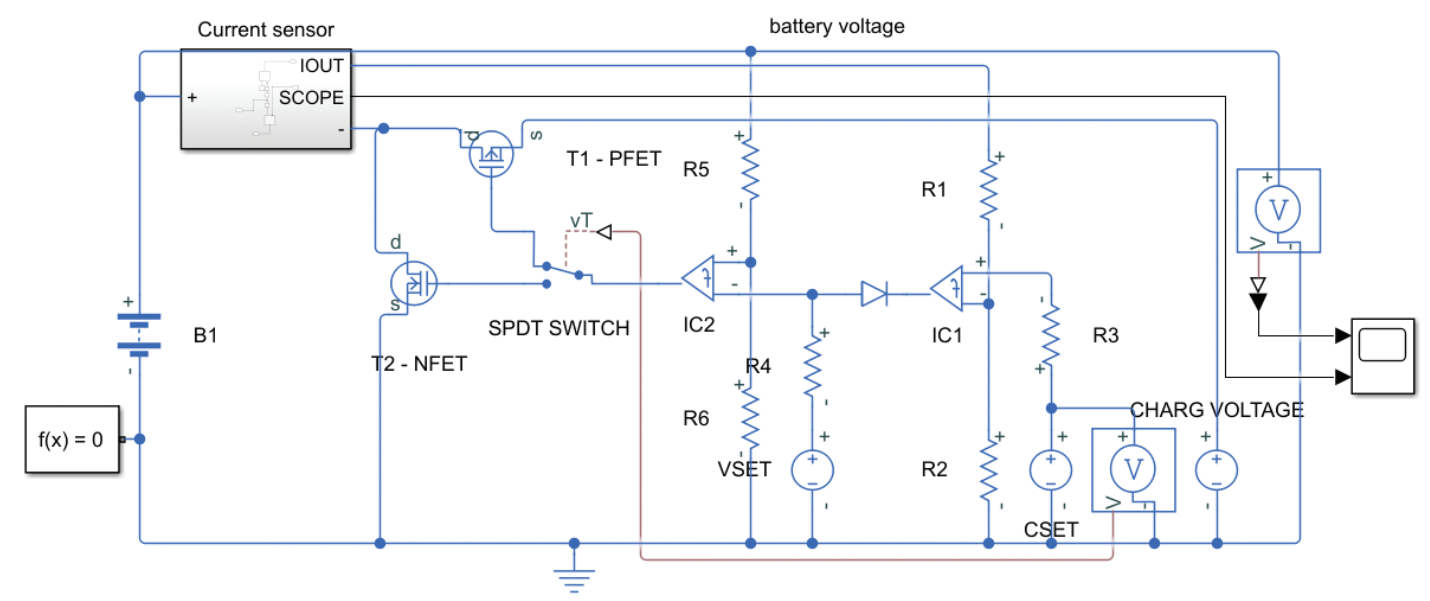

Fig. 12. Simulation schematic: $C C / C V$ charging and $C C$ discharging.

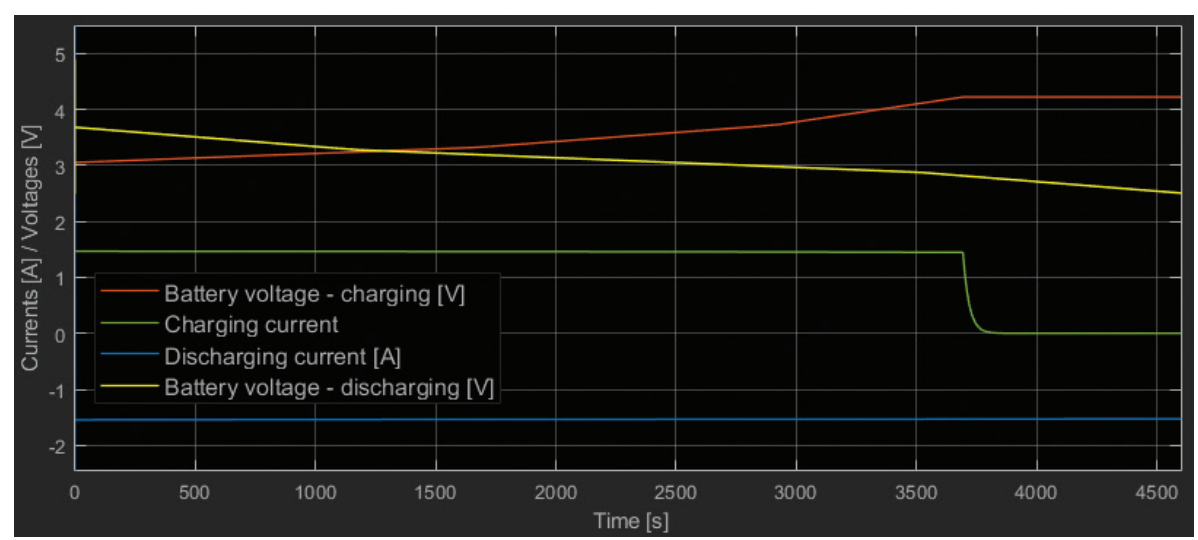

Fig. 13. Simulation output: CC/CV charging and CC discharging; at the time around $3700 \mathrm{~s}$ charging

since there is no overvoltage on the battery during charging. According to the simulation output depicted in Figure 13, it is possible to say that the charging circuit operates in CC/CV mode.

\subsubsection{MOSFETS selection}

It is necessary to add parameters from the available MOSFETs to the settings of the MOSFET blocks in Simscape. The circuit controls the transistors in the linear region; thus, it is clear that there will be losses on them, and therefore it is appropriate to properly dimension them. 18,650 batteries will be used. Batteries with a maximum capacity of $3,000 \mathrm{mAh}$ are currently available; thus, $1 \mathrm{C}=3 \mathrm{~A}$. It is advisable to test the battery with discharge currents up to $5 \mathrm{C}$; therefore, a MOSFET that can handle a current of at least $15 \mathrm{~A}$ needs to be chosen. MOSFET losses can be calculated using the following formula for performance:

$$
\mathrm{P}_{\text {disch }}=\mathrm{U}_{\text {batmax }} * \mathrm{I}_{\text {dischmax }}=4.2 \mathrm{~V} * 15 \mathrm{~A}=63 \mathrm{~W}
$$

This is the worst-case scenario that occurs when the battery is fully charged, and the discharge current is at a maximum. Based on these calculations, the IRFZ34 MOSFET was selected, which meets all the required properties. Important parameters and the setting of the MOSFET block are shown in Figures 14 and 15.

During charging, the situation is slightly different since the charging currents are a maximum of $2 \mathrm{C}$, which means that for batteries with a capacity of $3000 \mathrm{mAh}$ is $2 \mathrm{C}=6 \mathrm{~A}$. It should be taken into account that the voltage on the transistor also changes during charging. Using Kirchhoff's second law, we derive the following equation:

$$
\mathrm{V}_{\text {charget }}=\mathrm{U}_{\text {chargsource }}-\mathrm{U}_{\text {batact }}
$$




\begin{tabular}{|c|c|c|c|c|c|c|c|c|}
\hline \multicolumn{6}{|c|}{ ABSOLUTE MAXIMUM RATINGS } & & & \\
\hline \multirow{2}{*}{\multicolumn{3}{|c|}{$\begin{array}{l}\text { PARAMETER } \\
\text { Drain-Source Voltage }\end{array}$}} & SYMBOL & LIMIT & UNIT & \multicolumn{3}{|c|}{ PRODUCT SUMMARY } \\
\hline & & & $V_{D S}$ & 60 & \multirow[b]{2}{*}{ V } & $V_{D S}(\mathrm{~V})$ & \multicolumn{2}{|c|}{60} \\
\hline \multicolumn{3}{|l|}{ Gate-Source Voltage } & $V_{G S}$ & \pm 20 & & $R_{D S(\text { on) }}(\Omega)$ & $V_{G S}=10 \mathrm{~V}$ & 0.050 \\
\hline \multirow{3}{*}{ Continuous Drain Current } & \multirow[b]{2}{*}{$V_{G S}$ at $10 \mathrm{~V}$} & $T_{C}=25^{\circ} \mathrm{C}$ & & 30 & \multirow{4}{*}{ A } & $Q_{g}(\operatorname{Max}).(\mathrm{nC})$ & \multicolumn{2}{|c|}{46} \\
\hline & & $T_{C}=100^{\circ} \mathrm{C}$ & $I_{D}$ & 21 & & $Q_{g S}(\mathrm{nC})$ & \multicolumn{2}{|c|}{11} \\
\hline \multirow{2}{*}{\multicolumn{3}{|c|}{ Pulsed Drain Current $^{\mathrm{a}}$}} & & & & $Q_{g_{d}}(\mathrm{nC})$ & \multicolumn{2}{|c|}{22} \\
\hline & & & $I_{D M}$ & 120 & & Configuration & \multirow{2}{*}{\multicolumn{2}{|c|}{ Single }} \\
\hline Maximum Power Dissipation & \multicolumn{2}{|c|}{$T_{C}=25^{\circ} \mathrm{C}$} & $P_{D}$ & 88 & W & & & \\
\hline
\end{tabular}

Fig. 14. Important parameters from the datasheet of IRFZ34 MOSFET (IRFZ34, 2019).

\begin{tabular}{|c|c|c|c|c|c|c|}
\hline Main & Ohmic Resistance & Junct & ion Capacitance & Body Diode & Temperature Dependence & \\
\hline \multicolumn{3}{|c|}{ Parameterization: } & \multicolumn{3}{|l|}{ Three terminals } & 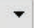 \\
\hline \multicolumn{3}{|c|}{ Terminals: } & \multicolumn{3}{|c|}{ Specify from a datasheet } & $\cdot$ \\
\hline \multicolumn{3}{|c|}{$\begin{array}{l}\text { Drain-source on resistance, } \\
\text { R_DS(on): }\end{array}$} & \multicolumn{3}{|l|}{0.05} & $\checkmark$ \\
\hline \multicolumn{3}{|c|}{ Drain current, Ids, for R_DS(on): } & \multicolumn{3}{|l|}{21} & $\checkmark$ \\
\hline \multicolumn{3}{|c|}{$\begin{array}{l}\text { Gate-source voltage, Vgs, for } \\
\text { R_DS(on): }\end{array}$} & \multicolumn{3}{|l|}{10} & $\checkmark$ \\
\hline \multicolumn{3}{|c|}{ Gate-source threshold voltage, Vth: } & \multicolumn{3}{|l|}{2} & $\checkmark$ \\
\hline \multicolumn{3}{|c|}{ Channel modulation, L: } & \multicolumn{3}{|l|}{0} & $\checkmark$ \\
\hline \multicolumn{3}{|c|}{ Measurement temperature: } & \multicolumn{3}{|l|}{25} & $\checkmark$ \\
\hline Main & Ohmic Resistance & Junct & tion Capacitance & Body Diode & Temperature Dependence & \\
\hline \multicolumn{3}{|c|}{ Parameterization: } & \multicolumn{3}{|c|}{ Specify fixed input, reverse transfer, and output capacitance } & - \\
\hline \multicolumn{3}{|c|}{ Input capacitance, Ciss: } & \multicolumn{2}{|l|}{1200} & $\mathrm{pF}$ & $\checkmark$ \\
\hline \multicolumn{3}{|c|}{$\begin{array}{l}\text { Reverse transfer capacitance, } \\
\text { Crss: }\end{array}$} & \multicolumn{2}{|l|}{100} & $\mathrm{pF}$ & $\checkmark$ \\
\hline \multicolumn{3}{|c|}{ Output capacitance, Coss: } & \multicolumn{2}{|l|}{600} & $\mathrm{pF}$ & $\checkmark$ \\
\hline \multicolumn{3}{|c|}{ Charge-voltage linearity: } & \multicolumn{3}{|c|}{ Gate-drain capacitance is constant } & . \\
\hline
\end{tabular}

Fig. 15. $T_{2}$ MOSFET block settings in Simscape.

In this case, the charging source has a value of $12 \mathrm{~V}$; so, in the worst possible case, when the battery is maximally discharged, we have:

$$
\mathrm{P}_{\text {charg }}=\mathrm{V}_{\text {chargfat }} * \mathrm{I}_{\text {chargmax }}=(12 \mathrm{~V}-2.5 \mathrm{~V}) * 6 \mathrm{~A}=57 \mathrm{~W}
$$

In the case of a $5 \mathrm{~V}$ charging source, the maximum power losses will decrease to:

$$
\mathrm{P}_{\text {charg }}=\mathrm{V}_{\text {chargetet }} * \mathrm{I}_{\text {chargmax }}=(5 \mathrm{~V}-2.5 \mathrm{~V}) * 6 \mathrm{~A}=15 \mathrm{~W}
$$

Based on these calculations, the IRF9Z24 MOSFET was selected, which meets all the necessary requirements. Important parameters and the setting of the MOSFET block are shown in Figures 16 and 17.

\section{Simulations}

In the previous section, parts of simulation models were designed. In this section, all these parts will be merged to create a final simulation schematic, as shown in Figure 18. 


\begin{tabular}{|c|c|c|c|c|c|c|c|c|}
\hline \multicolumn{6}{|c|}{ ABSOLUTE MAXIMUM RATINGS } & \multicolumn{3}{|c|}{ PRODUCT SUMMARY } \\
\hline \multirow{2}{*}{\multicolumn{3}{|c|}{\begin{tabular}{|l} 
PARAMETER \\
Drain-Source Voltage
\end{tabular}}} & \multirow{2}{*}{\begin{tabular}{|c|} 
SYMBOL \\
$V_{D S}$ \\
\end{tabular}} & \multicolumn{2}{|c|}{ LIMIT UNIT } & $V_{D S}(\mathrm{M})$ & \multicolumn{2}{|c|}{-60} \\
\hline & & & & -60 & V & $R_{D S(\text { on) }}(\Omega)$ & $V_{G S}=-10 \mathrm{~V}$ & 0.28 \\
\hline \multicolumn{3}{|l|}{ Gate-Source Voltage } & $V_{G S}$ & \begin{tabular}{|r|} 
\pm 20 \\
11
\end{tabular} & V & $Q_{g}$ (Max.) (nC) & \multicolumn{2}{|c|}{19} \\
\hline Continuous Drain Current & $V_{G S}$ at $-10 \mathrm{~V}$ & $\begin{array}{c}T_{C}=25^{\circ} \mathrm{C} \\
T_{C}=100^{\circ} \mathrm{C}\end{array}$ & $I_{D}$ & \begin{tabular}{|l|}
-11 \\
-7.7 \\
\end{tabular} & \multirow[t]{2}{*}{ A } & $Q_{g S}(\mathrm{nC})$ & \multicolumn{2}{|c|}{5.4} \\
\hline \multicolumn{3}{|l|}{ Pulsed Drain Current $^{\mathrm{a}}$} & $I_{D M}$ & -44 & & $Q_{g_{d}}(\mathrm{nC})$ & \multicolumn{2}{|c|}{11} \\
\hline Maximum Power Dissipation & \multicolumn{2}{|c|}{$T_{C}=25^{\circ} \mathrm{C}$} & $P_{D}$ & 60 & W & Configuration & \multicolumn{2}{|c|}{ Single } \\
\hline
\end{tabular}

Fig. 16. Important parameters from the datasheet of IRF9Z24 MOSFET (IRF9Z24, 2019).

\begin{tabular}{|c|c|c|c|c|c|c|}
\hline Main & Ohmic Resistance & Juncti & tion Capacitance & Body Diode & Temperature Dependence & \\
\hline \multicolumn{3}{|c|}{ Parameterization: } & \multicolumn{3}{|l|}{ Three terminals } & - \\
\hline \multicolumn{3}{|c|}{ Terminals: } & \multicolumn{3}{|c|}{ Specify from a datasheet } & - \\
\hline \multicolumn{3}{|c|}{$\begin{array}{l}\text { Drain-source on resistance, } \\
\text { R_DS(on): }\end{array}$} & \multicolumn{3}{|l|}{0.28} & $\checkmark$ \\
\hline \multicolumn{3}{|c|}{ Drain current, Ids, for R_DS(on): } & \multicolumn{3}{|l|}{-7.7} & $v$ \\
\hline \multicolumn{3}{|c|}{$\begin{array}{l}\text { Gate-source voltage, Vgs, for } \\
\text { R_DS(on): }\end{array}$} & \multicolumn{3}{|l|}{-10} & $\checkmark$ \\
\hline \multicolumn{3}{|c|}{ Gate-source threshold voltage, vth: } & \multicolumn{3}{|l|}{-2} & $v$ \\
\hline \multicolumn{3}{|c|}{ Channel modulation, L: } & \multicolumn{3}{|l|}{0} & $\checkmark$ \\
\hline \multicolumn{3}{|c|}{ Measurement temperature: } & \multicolumn{3}{|l|}{25} & $\checkmark$ \\
\hline Main & Ohmic Resistance & \multicolumn{2}{|c|}{ Junction Capacitance } & Body Diode & Temperature Dependence & \\
\hline \multicolumn{3}{|c|}{ Parameterization: } & \multicolumn{3}{|c|}{ Specify fixed input, reverse transfer, and output capacitance } & 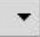 \\
\hline \multicolumn{3}{|c|}{ Input capacitance, Ciss: } & \multicolumn{2}{|l|}{570} & $\mathrm{pF}$ & $\checkmark$ \\
\hline \multicolumn{3}{|c|}{$\begin{array}{l}\text { Reverse transfer capacitance, } \\
\text { Crss: }\end{array}$} & \multicolumn{2}{|c|}{65} & $\mathrm{pF}$ & $\checkmark$ \\
\hline \multicolumn{3}{|c|}{ Output capacitance, Coss: } & \multicolumn{2}{|l|}{360} & $\mathrm{pF}$ & $\checkmark$ \\
\hline \multicolumn{3}{|c|}{ Charge-voltage linearity: } & \multicolumn{3}{|c|}{ Gate-drain capacitance is constant } & 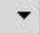 \\
\hline
\end{tabular}

Fig. 17. $T_{1}$ MOSFET block settings in Simscape.

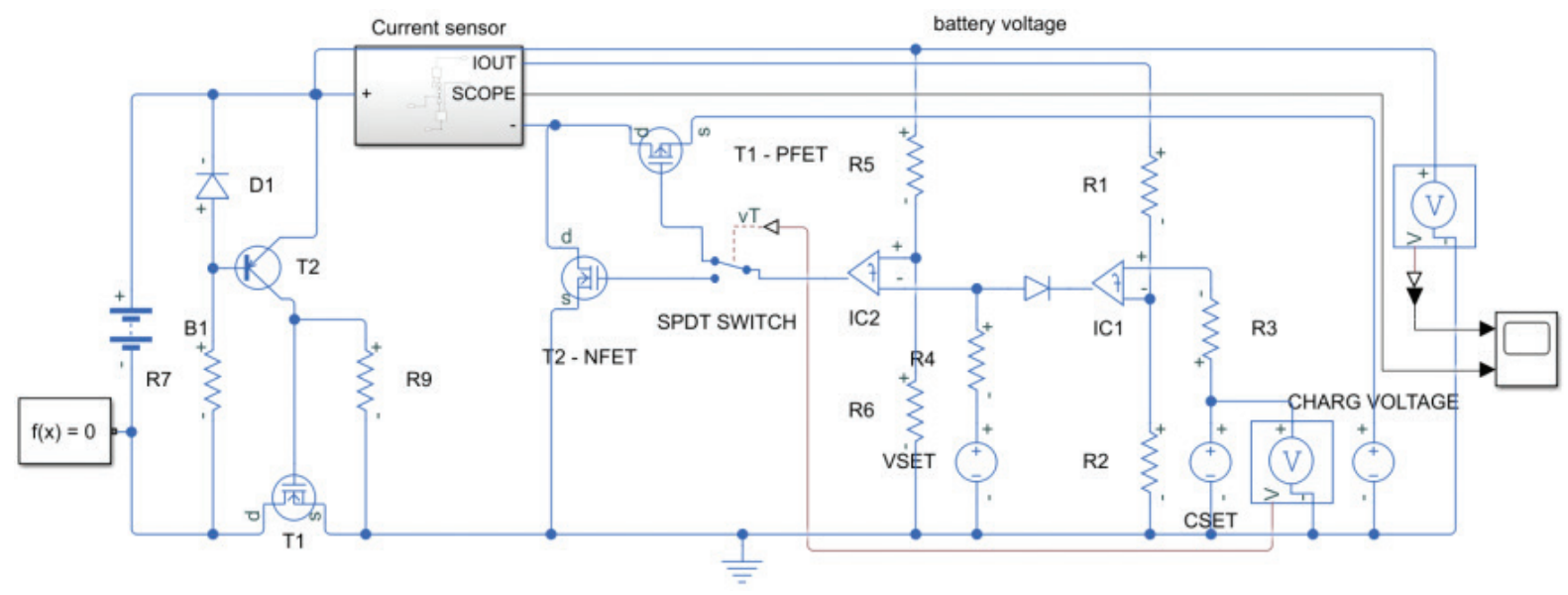

Fig. 18. Final simulation schematic in Simscape. 


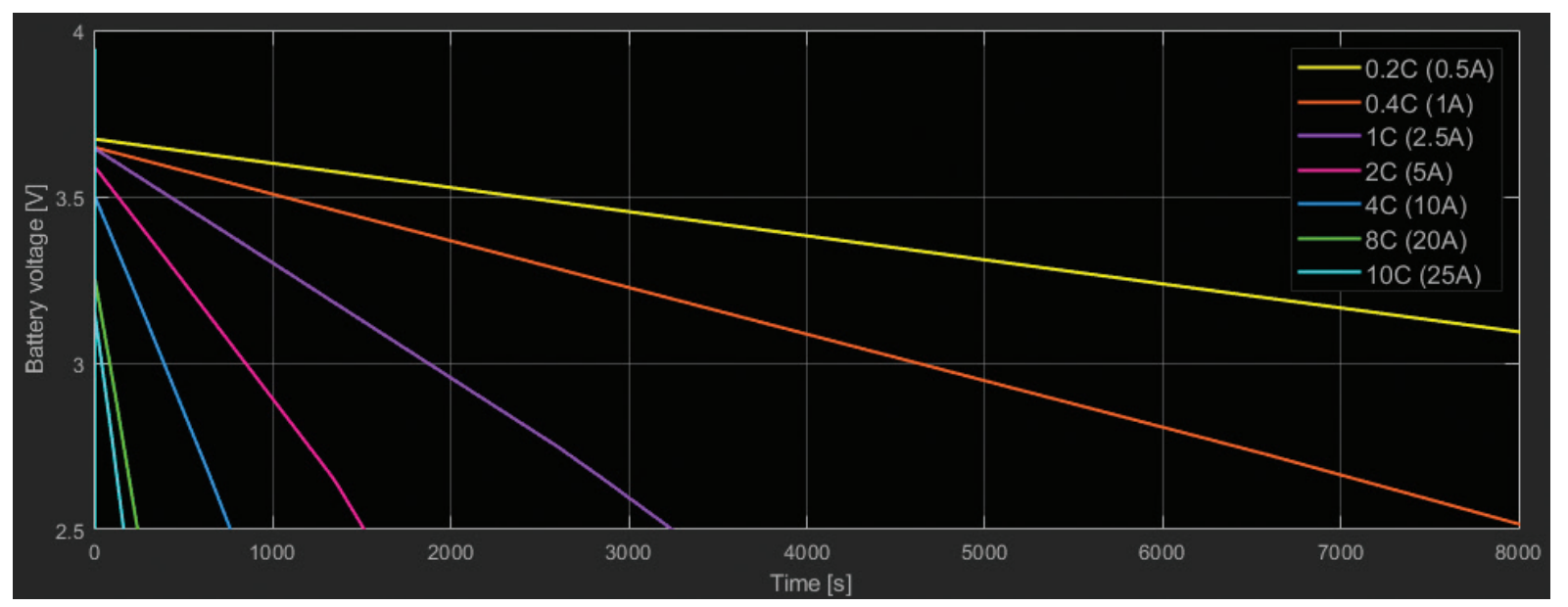

Fig. 19. Simulating discharging the battery using a designed circuit.

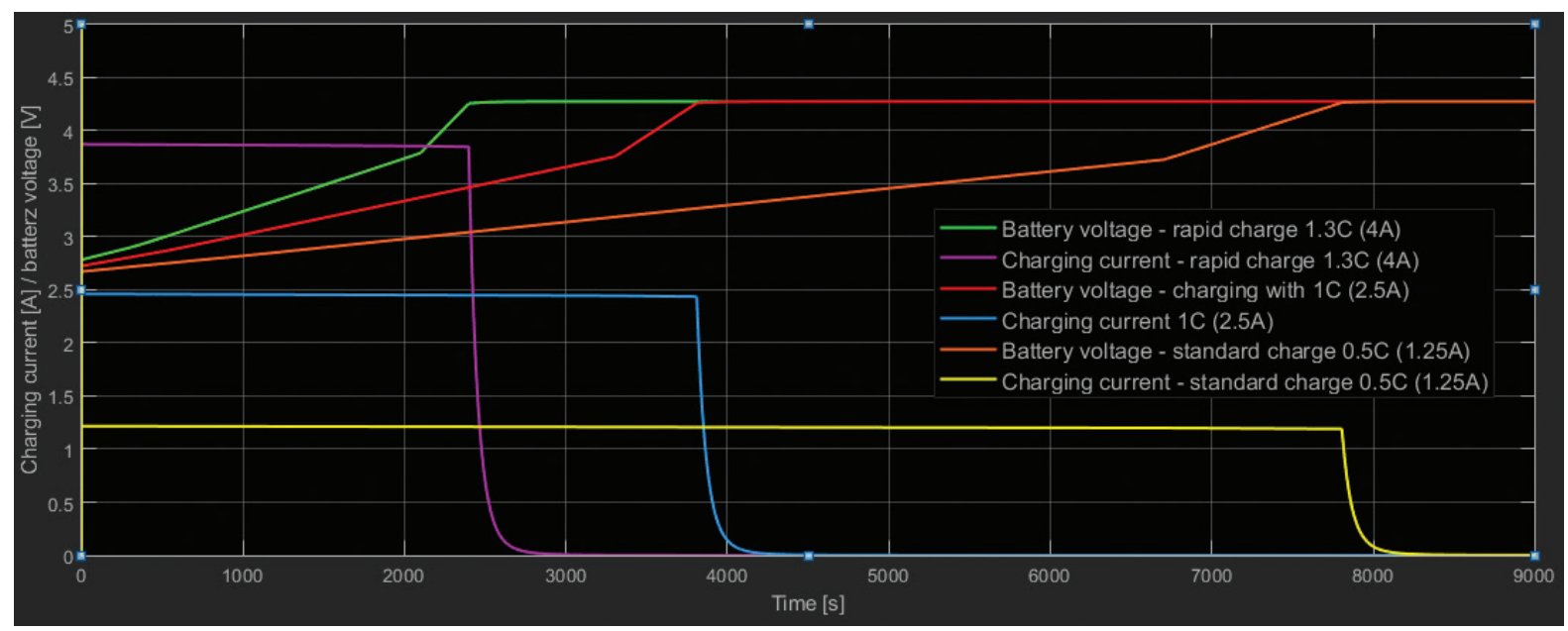

Fig. 20. Simulating charging the battery using a designed circuit.

\section{Conclusion}

The article is focused on Li-ion batteries and their testing. The article describes the correct process of charging and discharging Li-ion batteries. In addition, a circuit has been designed in the Simscape simulation program which is capable of cyclically charging and discharging the battery, thus being able to test it cyclically. Proofs of the circuitry functionality are provided by way of the outputs of the simulations in Figures 19 and 20, from which it is possible to observe discharging at different discharge currents up to almost zero capacity and also charging in CC/CV mode with different currents. Our future task is to construct such a cyclic tester, in real conditions and on real hardware, using the obtained scheme from simulations.

\section{Acknowledgments}

This work was supported by the Slovak Research and Development Agency under Contract No. APVV-18-0436 and by the Faculty of Electrical Engineering and Informatics, Technical University of Kosice, under Grant 04/TUKE/2020. 


\section{References}

Anon. (2020). The BatteryGuy.com Knowledge Base, [online]. Available at: https://batteryguy.com/kb/ knowledge-base/a-history-of-the-battery/

Bil'anský, J., 2020. Overview of the Battery Types and their Testing. In: SCYR - Nonconference Proceedings of Young Researchers. Košice: s.n., pp. 143-146.

Hsieh, Y.-C., Wu, J.-L. and Kuo, Q.-Y. (2011). A Li-ion battery string protection system. In: International Conference on Applied Electronics. Pilsen, Czech Republic:s.n., pp. 1-4.

INR18650-25R. (2014). Samsung SDI Co., Ltd. [online]. Available at: https://www.tme.eu/Document/ d 5041798 b 4 1 b6ad5e98cd9d1377d272d/ INR18650-25R.pdf.

IRF9Z24. (2019). Vishay Intertechnology, Inc. [online]. Available at: https://www.vishay.com/docs/ 91090/91090.pdf.

IRFZ34. (2019). Vishay Intertechnology, Inc. [online]. Available at: https://www.vishay.com/docs/91290/ 91290.pdf.

Khan, A. B., Phan, V. L., Nguyen, T. T. and Choi, W. (2016). Multistage constant-current charging method for Li-ion batteries. In: IEEE Transportation Electrification Conference and Expo. Asia-Pacific (ITEC Asia-Pacific): s.n., pp. 381-385.

Luan, Shang-Wen, Teng, Jen-Hao, Lee, Dong-Jing; Huang, Yong-Qing, Sung, Chen-Lin, (2011). Charging/discharging monitoring and simulation platform for Li-ion batteries. In: TENCON IEEE Region 10 Conference. Bali, Indonesia:s.n., pp. 868-872.
Mahmoud, A. M. and Osama, M. (2011). A Three-Phase High Frequency Semi-Controlled Battery Charging Power Converter for Plug-In Hybrid Electric Vehicles. Journal of Power Electronics, 11, pp. 2641-2648.

Meena, N., Baharwani, V., Sharma, D., Sharma, A., Choudhary, B., Parmar, P., Stephen, R. B., (2014). Charging and discharging characteristics of Lead acid and Li-ion batteries. In: Power and energy systems: Towards sustainable energy. Bangalore, India:s.n., pp. 1-3.

Si7858BDP. (2019). Vishay Intertechnology, Inc. [online]. Available at: https://www.vishay.com/docs/66589/ si7858bd.pdf.

Tar, B. and Fayed, A. (2016). An overview of the fundamentals of battery chargers. In: IEEE 59th International Midwest Symposium on Circuits and Systems (MWSCAS). Abu Dhabi, United Arab Emirates:s.n., pp. 1-4.

Wey, C. and Jui, P. (2013). A unitized charging and discharging smart battery management system. In: International Conference on Connected Vehicles and Expo (ICCVE). Las Vegas, NV, USA:s.n., pp. 903-909.

Xiong, J., Banvait, H., Li, L., Chen, Y., Xie, J., Liu, Y., Wu, M., Chn, J., (2012). Failure detection for overdischarged Li-ion batteries. In: IEEE International Electric Vehicle Conference. Greenville, SC, USA:s.n., pp. 1-5.

Ye, Z., Wu, X., Sun, Y. and Lu, J. (2010). A universal protection controller for Li-ion battery charger. In: Asia-Pacific Power and Energy Engineering Conference. Chengdu, China:s.n., pp. 1-4. 